\title{
Buracos Negros na Formação Inicial de Professores de Matemática
}

\author{
Black Holes in Initial Math Teachers Training
}

\author{
Carla Gonçalves Rodrigues* \\ Josimara Wikboldt Schwantz ${ }^{* *}$
}

\begin{abstract}
Resumo
A implementação de Diretrizes Curriculares Básicas revigorou antigas rotinas escolares, fazendo surgir outros modos de ver, ouvir e narrar constituintes das subjetivações professorais. Nesse sentido, o trabalho com projetos de ensino de onze estagiários do Curso de Licenciatura em Matemática da UFPel favoreceu o desenvolvimento deste texto. Este estudo utiliza o método investigativo cartográfico para acompanhar processos de subjetivação na formação inicial de professores de Matemática através de dispositivos como observações participantes, questionários orientadores de narrativa e encontros temáticos com o grupo. Os dados foram coletados durante o ano letivo relativo à tal formação, e sua análise deu-se segundo conceitos desenvolvidos na filosofia de Deleuze e Guattari. O campo problemático que fomentou este exercício cartográfico detectou pontos denominados buracos negros do autoritarismo, da docência circular e da avaliação punitiva, em que o fluxo criativo das práticas docentes foi estagnado, interrompendo os processos inovadores, reincidindo em funcionamentos molarizados.
\end{abstract}

Palavras-chave: Formação Docente. Projetos de Ensino. Processos de Subjetivação. Cartografia.

\begin{abstract}
The basic curriculum guidelines implementation renewed old school routines, encouraging the emergency of other ways of seeing, listening and narrating constituents of teaching subjectivities. In this sense, the work with teaching projects of eleven trainees of Mathematics course at UFPel favored the developing of this text. This study uses the investigative cartographic method to follow subjectivities projects in Mathematics teachers early training through devices like participants observations, oriented narratives questionnaires and theme meeting with the group. The data were collected during the school year related to such formation, and its analysis took place according to the concepts developed by the Deleuze and Guattari philosophy. The problematic field that fostered this cartographic exercise detected points known as black holes of authoritarianism, circular decency and punitive evaluation, in which creative flow of teaching practices was stuck, interrupting the innovative processes relapsing in molarized functioning.
\end{abstract}

Keywords: Teaching training. Teaching projects. Subjectivities processes. Cartography.

\footnotetext{
* Doutora em Educação pela Universidade Federal do Rio Grande do Sul (UFRGS). Professora da Faculdade de Educação e do Programa de Pós-Graduação em Educação da Universidade Federal de Pelotas (UFPel), Pelotas, Rio Grande do Sul, Brasil. Endereço para correspondência: Avenida Dom Joaquim, 529, apt 301, Três Vendas, Cep: 96020-260, Pelotas/RS. Email: cgrm@ufpel.edu.br

${ }^{* *}$ Doutoranda em Educação pela Universidade Federal de Pelotas (UFPel). Professora na Escola Estadual de Ensino Fundamental Dona Gabriela Gastal, Capão do Leão, Rio Grande do Sul, Brasil. Endereço para correspondência: Avenida Cidade de Lisboa, 241, Fragata, Cep: 96045-020, Pelotas, RS. Email: josiwikboldt@hotmail.com
} 
Nada sai de um buraco negro ${ }^{1}$, isto é, nada do que acontece internamente em um buraco negro chega diretamente até nós. Esta é a ideia prioritária apresentada pelos estudos físicos e astronômicos sobre tais estrelas ocluídas. É possível perceber os efeitos dessa cavidade atentando para os elementos que a rodeiam sob a ação do seu campo gravitacional. Se alcançássemos observar uma queda real de um objeto numa fenda desse tipo, de acordo com as simulações virtuais, veríamos o referido objeto mover-se cada vez mais devagar à medida que se aproximasse do núcleo massivo.

De forma muito simplista, podemos dizer que um buraco negro é uma região no espaço que contém tanta massa concentrada que nenhum objeto consegue dali escapar. Sua organização se dá a partir da declinação da força estelar capaz de opor-se à força gravitacional; a força competente decresce para resistir à gravitação. Desse modo, a matéria do astro adensa-se no seu centro e a estrela é dada por "morta". Dentro de certa distância em volta da estrela, qualquer coisa (incluindo a luz) é atraída e engolida, constituindo um buraco aqui denominado buraco negro.

A ideia imediata do conceito de buraco negro potencializa nosso pensamento sobre os

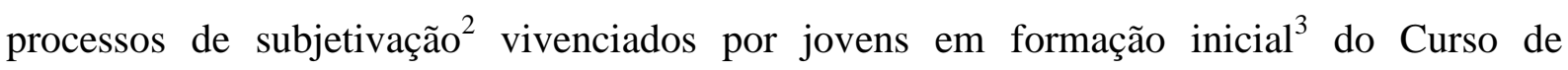
Licenciatura em Matemática da Universidade Federal de Pelotas. É nesse ambiente de estudo e de pesquisa que esta investigação cartográfica ${ }^{4}$ foi desenvolvida. A turma era formada por onze alunos que realizavam seus estágios docentes, sendo três rapazes e oito moças, com idade média de vinte anos. Apenas uma estagiária possuía formação em Magistério, o que lhe possibilitava atuar em sala de aula nos Anos Iniciais de uma escola da rede pública municipal, ao mesmo tempo em que realizava sua formação universitária. Mesmo assim, a referida aluna compôs o grupo de sujeitos (estagiários), visto que sua atuação docente também foi tida como inicial pelo pouco tempo de trabalho que ela exercera até o presente momento.

Durante a investigação, a turma foi assistida por duas professoras da Universidade, sendo que uma atuava na condição de substituta. Os dispositivos utilizados para o acompanhamento dos processos de formação docente do grupo em questão foram:

\footnotetext{
${ }^{1}$ O nome "buraco negro" foi popularizado por John Archibald Wheeler (2015). Antes da denominação efetuada por Wheeler, esses objetos eram conhecidos como "estrelas ocluídas".

2 “A subjectivação nem sequer tem que ver com a $<<$ pessoa $>>$ : é uma individuação, particular ou colectiva, que caracteriza um acontecimento [...]. É um modo intensivo e não um sujeito pessoal. É uma dimensão específica sem a qual não se poderia ir além do saber nem resistir ao poder" (DELEUZE, 1996, p. 77)

3 A concepção de formação inicial de professores aqui adotada refere-se a uma das fases de um processo de desenvolvimento contínuo do professor, denominada pré-serviço.

${ }^{4}$ A cartografia é um método formulado por Gilles Deleuze e Félix Guattari (2000) que visa acompanhar um processo, e não representar um objeto. Este método vem sendo utilizado no Brasil em pesquisas de campo (PASSOS; KASTRUP; ESCÓSSIA, 2009; ROLNIK, 1989) voltadas para o estudo da subjetividade.
} 
observações participantes, questionários orientadores dos relatos e encontros temáticos com o grupo focal. Considerando que a pesquisa cartográfica é bem menos informativa e mais um contar sobre aquilo que se passa em nós, isto é, um contar de dentro da experiência vivida, entendeu-se que esses dispositivos, selecionados para coleta de dados, estavam em consonância com a metodologia de pesquisa escolhida. Cabe lembrar que tal metodologia convida à invenção de um método próprio para cada investigação, segundo a temática estudada.

A cartografia tem por objetivo, além de levantar dados qualitativos na produção de conhecimentos, acompanhar o próprio processo da investigação, pesquisando a experiência. Tanto o pesquisador quanto o objeto a ser pesquisado estão intimamente implicados no ato da busca (PASSOS et al, 2009). Ela reverte o sentido tradicional de metodologias de pesquisa, tratando-se de um "caminhar que traça, no percurso, suas metas" (PASSOS et al, 2009, p. 17). Seu ponto de apoio é a experiência, enquanto plano de intervenção e de análise, compondo um saber que emerge do fazer.

No processo de produção de conhecimento, há que se colocar em evidência os atravessamentos que arranjam um campo de pesquisa. Na cartografia, o cartógrafo está sempre implicado e sua intervenção o modifica e altera seu objeto de estudo. A intervenção favorece a propagação de forças que emanam dos processos de institucionalização. É com esse plano concreto da experiência que, como pesquisadoras, estamos implicadas no referido processo. Quanto ao trabalho de análise, torna-se um momento de descrição, intervenção e criação de efeitos subjetivos que produzem novos arranjos de realidade num movimento de desestabilização dos padrões imersos no plano daquela experiência, indica Passos et al. (2009, p. 27).

Dessa maneira, visualizamos o trabalho direcionado aos estagiários dentro de uma dimensão coletiva, que é processual ao compor uma participação grupal "para além das dicotomias e das formas hegemônicas de organização da comunicação nas instituições: para além da verticalidade que hierarquiza os diferentes e da horizontalidade que iguala e homogeneíza um "espírito de corpo"” (KASTRUP; PASSOS, 2013, p. 264).

Com este estudo, realizado com o olhar atento à formação docente, pretendemos abordar os movimentos produzidos pelas forças que afetam os professores envolvidos na pesquisa durante sua formação inicial. De outro modo, podemos dizer que a problemática que nos deslocou enquanto cartógrafas estava mais voltada para detectar os pontos em que o fluxo potencializador das práticas docentes é estagnado, as paradas em que a força "estelar" é diminuída. Assim, o professor iniciante afasta-se dos seus processos criativos, reincidindo em 
modos de funcionamento professorais molarizados, habitando, predominantemente, uma linha formada por segmentos duros, aqui também sendo entendida como o delineamento de um espaço negro.

Ora, desde a segunda metade da década de 90, foram intensificados os debates acerca da formação de professores no Brasil. A Lei de Diretrizes e Bases da Educação Nacional (LDBEN) (BRASIL, 1996) indicou inovações para os cursos envolvidos com a constituição dos saberes docentes. O Plano Nacional de Educação (PNE) (BRASIL, 2001), fundamentado na LDBEN, enunciou proposições e apresentou diretrizes e metas relevantes para a formação de professores.

No PNE de 2001, encontra-se a narrativa de que "na formação inicial é preciso superar a histórica dicotomia entre teoria e prática e o divórcio entre a formação pedagógica e a formação no campo dos conhecimentos específicos que serão trabalhados na sala de aula" (BRASIL, 2001, p. 141). No plano estão, também, elencados os princípios norteadores dos cursos de formação de professores. São eles: ampla formação cultural, atividade docente como foco formativo, contato com a realidade escolar desde o início até o final do curso, interligando a teoria e a prática pedagógica, pesquisa como princípio formativo, domínio das novas tecnologias de comunicação-informação e capacidade para aplicá-las à prática do magistério superior.

Com isso, evidencia-se a relevância do exercício docente como forte elemento na formação de professores, tal como elemento de reflexão, estudo e pesquisa dos processos vivenciados na relação do professor iniciante com a escola. $\mathrm{O}$ ambiente escolar torna-se um potente local para aprendizagens, "desaprendizagens" e reaprendizagens articuladoras da teoria e da prática, podendo ser tida como um locus produtor de experiências e de saberes de experiência (LARROSA, 2002) através da realidade, mais do que um lugar de aplicação, verificação de técnicas e competências.

No ano de 2000, o Conselho Nacional de Educação voltou a intensificar os debates, redefinições e reformulações no que diz respeito às Diretrizes para a Formação de Professores da Educação Básica em cursos de nível superior. Em fevereiro de 2002, foram homologadas as Resoluções CNE/CP 1 (BRASIL, 2015a) e CNE/CP 2 (BRASIL, 2015b) que estabelecem tais diretrizes. Destacam as referidas resoluções a flexibilização curricular, a interdisciplinaridade e a pesquisa como foco do processo ensino-aprendizagem. Da mesma maneira, entendem a prática como uma dimensão que transcende o estágio curricular com ênfase nos procedimentos de observação e reflexão, visando à atuação em situações contextualizadas. Os registros dessas observações, a ação-reflexão-ação são vistos como 
princípio metodológico da formação dos docentes. A resolução de situações-problema é considerada, também, como uma das estratégias didáticas privilegiadas.

Desse modo, mais uma vez, é possível focalizar as questões relativas à prática do professor iniciante na escola como um princípio norteador do seu trabalho docente. A vivência no espaço escolar é compreendida como fomentadora da pesquisa, bem como dos mais variados processos reflexivos produtores de narrativas, de registros sobre a escola, de ações educativas desde os sujeitos envolvidos.

Para complementar o conjunto de textos legais, dá-se, a posteriori, a edição das Diretrizes Curriculares Nacionais para os diferentes cursos superiores de graduação (BRASIL, 2015c). Tais diretrizes determinam a natureza e as características das reformulações requeridas na formação inicial de professores da Educação Básica, definem alguns componentes curriculares, determinam a duração e a distribuição da carga horária em atividades de trabalho acadêmico e atividades práticas.

Esses princípios e procedimentos produzem movimentos que provocam tensão nas concepções de formação docente. Por tais razões, procuramos reunir essas recomendações no argumento de experimentarmos planejar e desenvolver projetos de ensino ${ }^{5}$ na preparação e na atuação do estágio supervisionado, em salas de aula de turmas de $6^{\circ}$ ano ${ }^{6}$, com foco na construção de conceitos geométricos elementares. Entendíamos que, no tempo e no espaço em que se constituíram os estágios, a concepção de trabalho pedagógico possibilitaria a formulação de propostas curriculares interdisciplinares, talvez até inovadoras para enfrentar a fragmentação disciplinar evidenciada nas escolas, articulando ensino e pesquisa, inclusive no período inicial do processo formativo.

Salientamos que esta pesquisa verificou-se em duas etapas interligadas. A primeira, denominada planejamento do projeto, destinada para os estagiários realizarem as observações ${ }^{7}$ na turma selecionada, efetuando registros sobre a prática a ser desenvolvida. Nessa fase, eles

\footnotetext{
${ }^{5} \mathrm{O}$ trabalho com projetos de ensino é, pois, uma metodologia investigativa centrada no fomento de problemas pertinentes para a turma com a qual estamos atuando pedagogicamente. Os projetos devem possibilitar novas aprendizagens e possuírem relação com o contexto em que vivem os alunos. Naturalmente, é necessário que sejam realizados com o tempo, as pessoas e os recursos disponíveis e acessíveis para o grupo, tratando-se de uma aprendizagem-ação, na qual o processo pode ser tanto ou mais importante que o produto (CASTRO; RICARDO, 1998; GONZÁLEZ, 1999; BONAFÈ, 1998).

${ }^{6}$ Antiga $5^{\mathrm{a}}$ série.

7 As observações foram realizadas em dupla de alunos-estagiários. A dupla foi constituída através do critério afinidade. Neste período, os alunos permaneciam na escola por uma tarde (cinco períodos) da semana. Com isso, eles conseguiram observar não apenas a aula de Matemática, mas quase todas as disciplinas e as rotinas da escola, tais como merenda, festividades, reuniões, horário de entrada e de saída, etc.
} 
estiveram acompanhados por meio de questionários, de encontros temáticos ${ }^{8}$ e sessões de orientação individual para a escrita dos projetos. Assim, obtivemos os projetos de ensino enfocando as seguintes temáticas: alimentação natural, graffiti, mosaicos, arquitetura da cidade, pandorgas, obras do artista Escher $^{9}$, embalagens, futebol, literatura infantil e construção civil.

$\mathrm{Na}$ segunda etapa, esses projetos foram desenvolvidos em duplas de estagiários nas turmas por eles observadas. Nesse momento o encontro com a ideia de buraco negro tornou-se potente para levar em conta os elementos da matéria com que investigamos a formação docente. Se, em um primeiro momento, pensávamos acompanhar processos inovadores na prática docente do ensino-aprendizagem da Matemática, foi somente a partir do mergulho naquilo que se passava na escola, e com os professores iniciantes por nós acompanhados, que nos deparamos com os buracos negros estagnadores de processos inovadores.

O modo de investigação cartográfica orientou-nos para um exercício formativo de um pesquisador desprovido de expectativas, de interesses por um resultado a ser encontrado: seria menos uma seleção in locus do previsto e mais uma atitude animal que nos coloca à espreita (DELEUZE; PARNET, 2001), deixando-se afetar pela experiência do vivido no encontro com o imprevisível. Foi com a atitude de cartógrafo, como professora-orientadora-pesquisadoraaprendiz, que aqui apresentamos modos de funcionamento que os professores iniciantes realizaram.

No que se refere à escolha das narrativas dos professores em relação às suas experiências no estágio, cabe destacar que estas operam de acordo com o próprio método cartográfico, trata-se de "uma posição que tomamos quando, em relação ao mundo e a si mesmo, definimos uma forma de expressão do que se passa, do que acontece" (PASSOS; BARROS, 2009, p. 151). A forma de expressão, articulada ao questionário e manifestada na fala dos professores, possibilitou-nos delinear três pontos que estamos denominando buraco negro do autoritarismo, da docência circular e da avaliação punitiva.

\footnotetext{
8 As temáticas abordadas foram: investigação qualitativa em educação, trabalho de campo, observação participante, registro das observações, planejamento de projetos de ensino, avaliação, currículo escolar, experiências bem sucedidas com projetos de ensino e escrita acadêmica educacional. Contamos com a presença e com os depoimentos sobre práticas docentes de professores em serviço, atuantes na rede pública de ensino da cidade de Pelotas. Leitura de contos, tais como Palomar de Calvino (1994), projeções dos documentários Ser e ter (Disponível em: https://www.youtube.com/watch?v=rbMQRGcYK64) e Janela da alma (Disponível em: https://www.youtube.com/watch?v=56Lsyci_gwg), também foram efetuados.

${ }^{9}$ Maurits Cornelis Escher foi um artista gráfico holandês conhecido pelas suas xilogravuras, litografias e meiostons (mezzotints), que tendem a representar construções impossíveis, preenchimento regular do plano, explorações do infinito e as metamorfoses - padrões geométricos entrecruzados que se transformam gradualmente para formas completamente diferentes. Disponível em: http://www.escher.eng.br/index_arquivos/Page345.htm
} 
Ainda queremos enfatizar que houve um distanciamento entre o planejado e o executado em sala de aula e que essa distância esteve preenchida por inúmeras brechas, crateras, fendas, ao modo de funcionamento dos buracos negros, e que muitas práticas docentes não conseguiram escapar à sua atração. Embora a intenção de trabalho com projetos de ensino estivesse permeada dos pensamentos de teóricos da área de conhecimento da Educação e da Educação Matemática, de reflexões e proposições inovadoras, na prática, ocorreram algumas submersões.

\section{Buraco negro do autoritarismo}

As atitudes de "colocar o aluno para fora da aula", falar com ele em tom de voz acentuado, assim como a utilização de gritos, foram alguns procedimentos que destoaram dos objetivos listados no Projeto sobre Alimentação Natural. Eu não estou conseguindo controlar a turma, repetia a professora iniciante durante as sessões com o grupo focal. Sua companheira de dupla completava seus argumentos, nas respostas do questionário que funcionou como dispositivo para esta pesquisa, afirmando: Tentamos conversar, falar alto, gritar. [...] Depois tivemos que suspender, pois não estava dando certo. O que realmente ajudou foi tirar um aluno da aula; assim a turma foi se acalmando aos poucos (Questionário 2 do grupo focal, 2012).

De alguma maneira, já sabemos que cada cultura escolar e cada atividade em sala de aula possuem um funcionamento adequado ao seu desenvolvimento. Dependendo da situação, o silêncio pode ser entendido por alguns docentes como uma postura que propicia ao aluno "alcançar" a tão almejada aprendizagem; por outras, tê-los perguntando, conversando entre si, transitando na sala, construindo hipóteses e estratégias de pensamento, também se torna, muitas vezes, um modo potente de fazer funcionar um pensamento.

Castro e Ricardo (1998) listam diferentes papéis ligados às variadas maneiras de poder exercidas pelos elementos do grupo de trabalho com projetos. Entre eles, temos o poder dos que gestam o projeto, dos que contribuem mais decisivamente para a sua realização, do professor coordenador das atividades em sala de aula, do poder ligado às competências técnicas, científicas, literárias, artísticas e aquele decorrente das relações nos meios onde se vão recolher as informações. Nessa perspectiva, o poder circula conforme ensinado por Foucault (1984).

Se antes importava "estabelecer as presenças e as ausências, saber onde e como encontrar os indivíduos, instaurar as comunicações úteis, interromper as outras, poder a cada 
instante vigiar o comportamento de cada um, apreciá-lo, sancioná-lo, medir as qualidades ou os méritos" (FOUCAULT, 1984, p. 131), com a prática de projetos de ensino, a autoridade não mais pertence exclusivamente ao professor, até então, aglutinador da atenção e do conhecimento. A soberania do docente deixa de estar alicerçada em um saber teórico e prático balizado pelo objetivo de manter a "boa ordem" e a "disciplina" em sala da aula.

Com isso, o processo de trabalho leva a uma redefinição das relações no espaço das práticas pedagógicas, propiciando aos alunos, em contexto escolar, a adoção de atitudes diferentes das que lhes estavam autorizadas nas aulas tradicionais, por exemplo, apenas escutar. A força do vigiar e punir é enfraquecida, fomentando o aprender a lidar com um aluno mais ativo, inquieto, "bagunceiro" e potencializado na sua capacidade inventiva. Mais do que isso, motivado pela novidade da descoberta em meio aos projetos vivenciados.

É fato que, nos cursos de formação docente, os professores iniciantes recebem muitas informações, tanto de caráter teórico como prático. São, inclusive, com essas informações que eles constroem articulações com suas propostas de ensino-aprendizagem. Conforme os dados coletados nesta investigação, diante da insegurança, dúvida e incerteza no que diz respeito ao itinerário que pretende orientar a sua atuação, o docente em formação inicial acaba caindo no buraco negro, isto é, fortalece experiências anteriores, até mesmo aquelas tidas como desagradáveis, neste caso, relativas ao autoritarismo: Eu acredito que só consigo superar a bagunça sendo, de certa forma autoritária, elevando o tom de voz. Eu não consigo ver uma outra saída para essa situação, até porque isso rende bons frutos (Questionário 8 do grupo focal, 2012).

Sem maiores dúvidas, existe uma forte articulação entre as experiências escolares e as formas de exercitar o trabalho docente. Aqui a teoria estudada e as proposições que esta suscita, dificilmente conseguem romper, fazer vazar, produzir linhas de fuga, mesmo quando o vivido na escola é tido como uma experiência negativa. $\mathrm{O}$ exercício da profissão professor encontra-se fortemente atrelado às experiências anteriores de aprendizagem (CATANI, 2005), favorecendo narrativas e ações como as acima apresentadas.

\section{Buraco negro da docência circular}

O que Jürgen Habermas (1984), filósofo e sociólogo alemão inserido na tradição da teoria crítica, chama de Projeto da Modernidade consolidou-se durante o século XVIII. Esse projeto equivalia a um esforço intelectual dos pensadores iluministas para desenvolver, universalmente, a ciência objetiva, a moralidade, a lei e a arte autônoma. Acreditava-se que o 
acúmulo de conhecimento, gerado pelo trabalho livre e criativo das pessoas, conduziria à emancipação humana. Defendia que o domínio científico da natureza, pelo homem, assegurava o atendimento das necessidades básicas, vencendo a escassez e as calamidades naturais (MANCEBO, 2015).

Mancebo (2015), ao realizar um debate sobre a modernidade e a produção de subjetividades, traça um percurso histórico que facilita a compreensão da própria constituição da modernidade. Segundo a autora, o pensamento iluminista preconizou o progresso. A ideia da racionalidade, aplicada ao desenvolvimento e à organização da sociedade, prometia a libertação de tudo aquilo tido como irracional: a religião, a superstição, o uso arbitrário do poder, etc. Diante dessa idealização iluminista, prosperaram doutrinas de igualdade, liberdade, crença na inteligência humana e na razão universal. Podemos dizer que o homem era concebido como fonte de suas representações e de seus atos, seu fundamento ou, ainda, autor de si mesmo.

Seguindo o breve percurso histórico acima exposto, enfrentamos, anteriormente, o $E u$ penso de Descartes, remetendo o ato de pensar ao eu empírico, sujeito particular dotado de pensamento natural em afinidade com o verdadeiro. É ele que possui a verdade e esta verdade está contida no seu pensamento de acordo com o Método (DESCARTES, 1996). Nessa direção, a crença na racionalidade instrumental passa a impor uma lógica de disciplinamento das relações da vida social, seja na esfera do trabalho, da família, seja na ou da escola, pautada na centralidade do sujeito abrigado em suas certezas.

Determinado por um ponto (o pensamento do professor) do qual tudo parte e, para tal, tudo retorna, o processo de tentativa de inovação pedagógica é engolido pela repetição nociva dessa circularidade que contém o conhecimento absoluto, irrefutável e inquestionável. A escrita do estagiário que trabalhou com o projeto sobre a arquitetura da cidade, quando questionado sobre os obstáculos enfrentados durante sua atuação em sala de aula, exemplifica o que estamos denominando buraco negro da docência circular: Eu ficava muito preocupado em seguir à risca o que estava planejado, deixando de aproveitar as contribuições dos alunos (Questionário 4 do grupo focal, 2012). "Eu concebo, eu julgo, eu imagino, eu percebo" assim nos ensinou o Cogito a produzir aquilo que somos e o que estamos em vias de ser: uma pessoa cartesiana, isto é, um docente cartesiano que passa a anular a capacidade de duvidar em prol do uso de um método fixado no seu pensamento, que exclui as contribuições dos discentes. 


\section{Buraco negro da avaliação punitiva}

Por que avaliamos nossos alunos? Para detectar problemas, entraves e, assim, definir prioridades? Para descobrirmos o que foi feito com êxito e o que ainda devemos fazer? Para estabelecer novas metas e objetivos? Tudo isso e mais um pouco. Também percebemos a avaliação como forma de punir a turma diante de alguma situação de descontentamento, desabando na profundeza do buraco negro que seleciona, exclui, marginaliza.

Tentamos fazer "combinados", fizemos regras. Nada disso funcionou, até que listamos conteúdos que cairiam na prova e dissemos que, enquanto eles não se acalmassem, não passaríamos a matéria, mas ela cairia na prova (Questionário 7 do grupo focal, 2012), registra a professora iniciante durante o desenvolvimento do projeto que visava integrar geometria com futebol. Precisamente, algum dos aspectos que conduzem a prática avaliadora dessa professora contradizem sua proposta inicial baseada nas ideias defendidas pela Pedagogia de Projetos de John Dewey (1978). Aqui, persiste a intenção da avaliação em acordo com outro tipo de planejamento educativo e que, definitivamente, paralisa a força da criação e a invenção do ensino e da aprendizagem na Matemática escolar.

Como castigo ao "mau" comportamento, a professora iniciante lançou um conteúdo enquanto "matéria dada", conteúdo este que não foi trabalhado em sala de aula e ameaçou cobrá-lo na prova. Atos perversos para o estabelecimento da ordem disciplinar fazem da avaliação uma ferramenta com fins muito distantes de sua função de fornecer dados para a tomada de decisões no que tange à aprendizagem dos alunos. Nessa perspectiva, a avaliação visa mais enaltecer o insucesso diante do não saber do que detectar formas de ensino adequadas para vigorar a aprendizagem.

Ressaltamos que o projeto aplicado em sala de aula, denominado "Matemática e Futebol", apresentou como intenção maior relacionar os conceitos de geometria elementar ao cotidiano dos alunos. A licencianda buscou fundamentação na teoria sociointeracionista de Vygotsky (1984), abordagem esta que tem amparado inúmeras pesquisas ${ }^{10}$ sobre o ensino de Matemática, instigando o professor a novas posturas sobre a construção histórica e social do conhecimento científico. Neste caso, evidenciamos a incongruência existente entre o discurso progressista empregado pela professora iniciante na construção dos seus objetivos de trabalho e a sua prática avaliativa conservadora, transformando, algumas vezes, seu processo de aprendizagem sobre o ato de ensinar em uma experiência que evidencia contradições entre intencionalidades e ações no cotidiano da sala de aula.

\footnotetext{
${ }^{10}$ Destacamos a pesquisa de Lúcia Moysés (1997).
} 


\section{Ainda sobre os buracos negros...}

Observamos movimentos governamentais da educação brasileira no que tange à formação docente, visando orientar o desenvolvimento técnico dos professores. Apesar dessas reformulações prescritivas, percebemos que se mantém a existência de buracos negros que engolem tentativas de inovação e criação nas práticas pedagógicas. Parece-nos que, de um lado, estamos vivendo um momento de incerteza, de dúvida, de verdade relativa; da informação que circula com velocidade assustadora e dos corpos agitados. De outro lado, continuamos impregnados dos efeitos das forças advindas da filosofia das luzes. Filosofia que se dedicou a demonstrar como o sujeito centrado, definido na sua essência, pode e deve, pela razão, corrigir seus desvios de ordem natural universal a fim de alcançar a tão almejada "verdadeira felicidade" no trabalho educacional.

Neste exercício investigativo, orientamos o trabalho dos professores iniciantes segundo alguns princípios interdisciplinares da Pedagogia de Projetos (DEWEY, 1978). Entendemos tal pedagogia como uma forma rizomática (DELEUZE; GUATTARI, 2000) de construir aprendizagens. Desse modo, o conhecimento constitui-se de múltiplas conexões que reúnem heterogêneos, diferentemente do modelo arborescente que tende à fixação de uma ordem estabelecida para $\mathrm{o}$ ato de conhecer.

O procedimento de agenciar convoca diferentes possibilidades de produzir um pensamento. Aqui a arte é envolvida para potencializar o movimento de criação. Já a filosofia cria conceitos. Isso auxilia na produção de imagens de pensamento em relação àquilo que se quer elaborar: uma poesia, uma música, uma história, etc. Essas produções se dão a partir de um plano de imanência, local onde se recolhem os elementos, de maneira que o seu arranjo constitui o conceito. A filosofia trata de orientar o pensamento a enfrentar os problemas construídos. Assim, o conceito se refere a um acontecimento que é mobilizado por aquilo que inquieta. Na ciência, são criados os functivos, que tratam da relação entre limite e variável, são as funções que conduzem à desaceleração do caos (DELEUZE; GUATTARI, 2010).

Proporcionamos-lhes, durante o período de atuação em sala, um experimentar de práticas estéticas atuais e de ideias filosóficas ${ }^{11}$. Acreditamos ser este um conjunto de dispositivos possíveis para reinventar seus modos de perceber o real e a si mesmos, naquilo

\footnotetext{
${ }^{11}$ No que diz respeito às práticas estéticas atuais, favorecemos o encontro com a literatura de Samuel Beckett, Clarice Lispector e Arnaldo Antunes; com o trabalho cinematográfico de Agnès Varda, João Jardim e Walter Carvalho. Dos conceitos filosóficos "deleuze-guattarianos", foi possível experimentar as ideias de "estar à espreita" segundo um estado que devém animal, bem como os conceitos de território, "desterritorialização" e "reterritorialização".
} 
em que o ato de ver, ouvir e narrar tem-se mostrado inepto e estagnador de diferenças. Talvez um arranjo de formas de expressão e formas de conteúdo agenciadoras de "artistagens" (CORAZZA, 2006) e um devir-filósofo nos movimentos subjetivos dos indivíduos participantes desta investigação.

Anteriormente, dissemos que o referido estudo foi conduzido por procedimentos metodológicos de acordo com a constituição do objeto investigado - processos de subjetivação de professores iniciantes que trabalham com a Matemática. Guiadas pelo modo cartográfico de fazer uma pesquisa, acompanhamos, além dos planos visíveis, os planos invisíveis da constituição de relações, condições e agenciamentos individuais e coletivos produtores de conhecimento (DELEUZE; GUATTARI, 2000).

A partir da experiência vivida, encontramo-nos com uma série de procedimentos divergentes do inicialmente indicado no planejamento das ações orientadoras das práticas docentes dos professores iniciantes. Listamos os buracos negros do autoritarismo, da docência circular e da avaliação punitiva como atitudes discrepantes das intenções apresentadas nos projetos de ensino.

Perguntamos: O que deu errado na nossa investigação-intervenção de formação desses professores? Não se trata de reduzir a experiência com o inesperado ao erro, como negativo do pensamento, ou ao resultado daquilo que se opõe ao pretendido. Um tanto vazou da comodidade que oferecem as hipóteses retas. Outro tanto se pôs a fugir naquilo que o bom senso, sob a forma de um senso comum, crê: promessas normalizadas nas atuais leis e diretrizes reguladoras da formação docente em prol da "felicidade eterna" no trabalho docente.

Sem maiores dúvidas, esta pesquisa diz respeito aos processos de formação de professores iniciantes e, também, aos processos de formação dos formadores de tais professores. Um exercício geográfico de encontros que dão o que pensar: cartografa-se ao cartografar o outro. Tensões no território de sentidos anteriormente habitado por nós foram potencializadas. Talvez se possa dizer de um deslocamento intensivo, um sacolejar nas referências, uma desconfiguração da narrativa, uma turbulência no campo perceptivo: uma desterritorialização, diriam Deleuze e Guattari (2002).

Toda perda de território pressupõe encontros intensivos e imprevisíveis que provocam, na corporeidade daquele que vive a experiência, um encharcamento, uma saturação, uma pressão causados pelas forças aí colocadas em movimento. Remete-se a algo que se passa em nós a partir de uma disposição para o sensível, acionando performances que estavam, até 
então, em baixa oscilação. Uma atenção para acontecimentos (KASTRUP, 2007), um olho vibrátil (ROLNIK, 1989) que permite atentar às forças que nos afetam.

O trabalho com os professores iniciantes serviu para fomentarmos a criação de condições para a produção de estados de percepção alterados nos modos molares de ver, ouvir e narrar. Não podemos oferecer garantias de que os dispositivos utilizados ativaram condições de disposição para praticar outras formas de relações consigo e com o coletivo. Contudo, podemos dizer que algo se mexeu entre a prática da Matemática escolar tida como tradicional e uma prática rizomática que se utilizou de projetos de ensino, mesmo que nos tenhamos deparado, em alguns momentos, com a invenção e a criação sendo devoradas por alguns buracos negros. É porque a variação dos modos de ser e estar no mundo, pensamos, não se encerra na disposição para tal atuação. Há, também, que suportar os efeitos causados pelos abalos dos territórios desconfigurados.

Perdido, o professor iniciante abriga-se como pode, tal como uma criança no escuro, tomada de medo. Orienta-se de acordo com o aumento do seu grau de potência ou conforme a diminuição. Quando ele fica enfraquecido na sua força cósmica, acaba deixando-se engolir pela massa negra, favorecendo a deterioração da matéria subjetiva.

Outro aspecto da construção de novos territórios habitáveis, de acordo com Deleuze e Guattari (2002), localiza-se a partir do traçado de um domínio, de um espaço limitado em que componentes bem diversos são reunidos: referências e marcas de todas as espécies. É possível pensar, de acordo com os autores, que,

\section{Agora, enfim, entreabrimos o círculo, nós o abrimos, deixa-se alguém entrar, chamamos alguém, ou então nós mesmos vamos para fora, nos lançamos. Não abrimos o círculo do lado onde vêm acumular-se as antigas forças do caos, mas numa outra região, criada pelo próprio círculo (DELEUZE; GUATTARI, 2002, p. 116-117).}

Ora, ora, ora... Se na apropriação física e astronômica realizada da ideia de buraco negro, entendíamos que nada dali poderia sair, ao passarmos a operar com o tratamento filosófico dado a tal ideia, podemos afirmar a concepção de que as forças estabelecidas coexistem com as formas moventes. Mesmo que as forças estabelecidas determinem paradas no processo inventivo, é possível desenhar um domínio referencial em torno desse ponto. $\mathrm{O}$ exercício de escuta daquilo que nos toca, da atenção para aquilo que nos passa, pode vir a demandar a dimensão processual potencializada de renovadas marcas territoriais, ao mesmo tempo em que se desativam outros modos de se relacionar com o mundo.

Há momentos em que encontramos o inesperado. São esses momentos de forte valorização de uma pesquisa. Algo acontece e a atenção é convocada. A atenção cartográfica, 
isto é, a atenção aberta à experiência e ao encontro do imprevisível acessa o campo de forças daquilo que nos acomete. É um longo trabalho de preparação, arranjos e desarranjos para constituição de um território político de formação de professores, segundo uma atitude de pesquisador.

\section{Referências}

BRASIL. Conselho Nacional de Educação. Institui diretrizes curriculares nacionais para a formação de professores da educação básica, em nível superior, curso de licenciatura, de graduação plena. Resolução CNE/CP 1, de 18 de fevereiro de 2002. Disponível em: <http:// portal.mec. gov.br/seesp/arquivos/pdf/res1_2.pdf>. Acesso em: 02 out. 2015.

BRASIL. Conselho Nacional de Educação. Institui a duração e a carga horária dos cursos de licenciatura, de graduação plena, de formação de professores da Educação Básica em nível superior. Resolução CNE/CP 2, de 19 de fevereiro de 2002. Disponível em: <http:// portal.mec.gov.br/cne/arquivos/pdf/CP022002.pdf>. Acesso em: 02 out. 2015.

BRASIL. Conselho Nacional de Educação. Orientação para as diretrizes curriculares dos cursos de graduação. Parecer CNE/CES n. 583, de 04 de abril de 2001. Disponível em: <http:// portal.mec.gov.br/cne/arquivos/pdf/CES0583.pdf>. Acesso em: 02 out. 2015.

BRASIL. Lei de Diretrizes e Bases da Educação Nacional. Lei n ${ }^{\circ} 9.394$, de 20 de dezembro de 1996.

BRASIL. Plano Nacional de Educação. Apresentado por Ivan Valente. Rio de Janeiro: DP\&A, 2001.

BONAFÈ, J. M. Proyectos curriculares y prática docente. 4. ed. Sevilla: Díada Editorial S. L. 1998.

CALVINO, I. Palomar. Tradução de I. Barroso. São Paulo: Companhia das Letras, 1994.

CASTRO, L. B.; RICARDO, M. M. C. Gerir o trabalho de projecto. 5. ed. Lisboa: Texto Editora, 1998.

CATANI, D. B. As leituras da própria vida e a escrita de experiências de formação. Revista da FAEEBA: educação e contemporaneidade, Salvador, v. 14, n. 24, p. 31-40, jul./dez. 2005.

CORAZZA, S. M. Artistagens: filosofia da diferença e educação. Belo Horizonte: Autêntica, 2006.

DELEUZE, G. O mistério de Ariana. Tradução de E. Cordeiro. Lisboa: Passagens, 1996.

DELEUZE, G.; GUATTARI, F. Mil platôs: capitalismo e esquizofrenia. v. 1. Tradução de A. G. Neto; C. P. Costa. Rio de Janeiro: Editora 34, 2000.

DELEUZE, G.; GUATTARI, F. Mil platôs: capitalismo e esquizofrenia. v. 2. Tradução de A. L. de Oliveira e L. C. Leão. São Paulo: Editora. 34, 1995.

DELEUZE, G.; GUATTARI, F. Mil platôs: capitalismo e esquizofrenia. v. 4. Tradução de S. Rolnik. Rio de Janeiro: Editora 34, 2002.

DELEUZE, G.; GUATTARI, F. O que é a filosofia? Tradução de B. P. Jr. e A. A. Muñoz. São Paulo: Editora 34, 2010. 
DELEUZE, G.; GUATTARI, F. Kafka: por uma literatura menor. Tradução de C. V. Silva. Belo Horizonte: Autêntica, 2014.

DELEUZE, G.; PARNET, C. L' Abécédaire de Gilles Deleuze. Entrevista com Gilles Deleuze. Editoração: Brasil, Ministério de Educação, "TV Escola", 2001. Paris: Editions Montparnasse, 1997. 1 videocassete, VHS, son., color.

DESCARTES, R. Discurso do método. São Paulo: Martins Fontes, 1996.

DEWEY, J. Vida e educação. Tradução de A. S. Teixeira. Rio de Janeiro: Fundação Nacional de Material Escolar, 1978.

FOUCAULT, M. Vigiar e punir: nascimento da prisão. 3. ed. Petrópolis: Vozes, 1984.

GONZÁLEZ, J. F. ¿Como hacer unidades didácticas innovadoras?. Sevilla: Diada Editorial S. L. 1999.

HABERMAS, J. Mudança estrutural da esfera pública. Rio de Janeiro: Tempo Brasileiro, 1984.

KASTRUP, V. O funcionamento da atenção no trabalho do cartógrafo. Psicologia e Sociedade, Rio de Janeiro, v. 19, n. 1, p. 15-22, jan./abr. 2007.

KASTRUP, V.; PASSOS, E. Cartografar é traçar um plano comum. Fractal: Revista de Psicologia, Niterói, v. 25, n. 2, p. 263-280, mai./ago. 2013.

LARROSA, J. Notas sobre a experiência e o saber da experiência. Revista Brasileira de Educação, Rio de Janeiro, n. 19, p. 20-28, jan./fev./mar./abr. 2002.

MANCEBO, D. Modernidade e produção de subjetividades. Disponível em: <https:// www.fe.unicamp.br/br2000/trabs/2010.doc >. Acesso em: 22 set. 2015.

MOYSÉS, L. Aplicações de Vygotsky à Educação Matemática. Campinas, SP: Papirus, 1997.

PASSOS, E.; KASTRUP, V.; ESCÓSSIA, L. Pistas do método cartográfico. Pesquisa-intervenção e produção de subjetividade. Porto Alegre: Editora Sulinas, 2009.

PASSOS, E.; BARROS, R. B. Por uma política da narratividade. In: PASSOS, E.; KASTRUP, V.; ESCÓSSIA, L. Pistas do método cartográfico. Pesquisa-intervenção e produção de subjetividade. Porto Alegre: Editora Sulinas, 2009.

ROLNIK, S. Cartografia sentimental: transformações contemporâneas do desejo. São Paulo: Estação Liberdade, 1989.

VYGOTSKY, L. S. Formação social da mente. São Paulo: Martins Fontes, 1984.

WHELLER. J. John Wheller 1911-2008. Disponível em: <http://www.astronoo .com/pt/biografias/john-wheeler.html>. Acesso em: set. 2015.

Submetido em Abril de 2015. Aprovado em Março de 2016. 